\title{
Predictors of healthcare professionals' intention and behaviour to encourage physical activity in patients with cardiovascular risk factors
}

\author{
Barbara Sassen ${ }^{1 *}$, Gerjo Kok ${ }^{2}$ and Luc Vanhees ${ }^{1,3}$
}

\begin{abstract}
Background: Healthcare professionals can play a crucial role in optimizing the health status of patients with cardiovascular risk factors (abdominal obesity, high blood pressure, low HDL cholesterol, elevated triglycerides and elevated blood glucose). In order to do this, it is imperative that we understand the social-cognitive determinants (including habits) that underlie healthcare professionals' intention and the corresponding behavior of actually encouraging patients with cardiovascular risk factors to engage in physical activity.

Methods: In this longitudinal Professionals' Intention and Behavior (PIB) study, healthcare professionals ( $N=278$, aged 20-61 years with approximately 60\% having attained an education level exceeding bachelor's degree, types of healthcare professionals $60 \%$ in physiotherapy and $40 \%$ in nursing) completed online surveys measuring the social-cognitive determinants of healthcare professionals' intention and the corresponding behavior of actually encouraging patients with cardiovascular risk factors to engage in physical activity.

Results: Social-cognitive determinants accounted for $41 \%(p<.001)$ of the variance in healthcare professionals' intention to encourage physical activity among cardiovascular patients. Important correlates of intention were attitude $(\beta=.443, p<.001)$, subjective norms $(\beta=.201, p<.001)$ and perceived behavioral control $\beta=.137, p<$ .01). With respect to the self-reported behavior of encouraging patients, social-cognitive determinants accounted for $29 \%(p<.001)$ of the variance. Intentions $(\beta=.311 p<.001)$, habit $(\beta=.163 p<.01)$, and barriers $(\beta=-.239 p$ $<.001)$ were significant correlates of professionals' behavior of encouraging patients to engage in physical activity. We explored the congruence between healthcare professionals' intention to encourage patients and the selfreported behavior of encouraging patients. We found that intention and behavior were congruent in $39.7 \%$ of the healthcare professionals. Additionally, the intention to encourage and the corresponding behavior of encouraging was incongruent in $31.7 \%$ of the healthcare professionals.

Conclusions: In the prevention of cardiovascular disease, healthcare professionals' intention to encourage physical activity among patients and subsequent behavior of encouraging patients is important for the improvement of patients' cardiovascular risk profiles. We found that the intentions and self-reported behavior of healthcare professionals working with patients with cardiovascular risk factors can be predicted by social-cognitive determinants thus implying that efforts to change and strengthen the intention-behavior relationship of healthcare professionals may have beneficial effects for cardiovascular risk patients (Trial ID: ECP-92).
\end{abstract}

\footnotetext{
* Correspondence: Barbara.Sassen@hu.nl

${ }^{1}$ Department of Health and Lifestyle, University of Applied Sciences, Utrecht, the Netherlands

Full list of author information is available at the end of the article
} 


\section{Background}

Healthcare professionals can play an essential role in optimizing the health status of patients with cardiovascular risk factors. However, a substantial gap between clinical research findings and the daily practice of healthcare professionals remains [1-7]. Though nowadays it is common to work evidence-based for healthcare professionals, the daily practice for healthcare professionals is sometimes different. In order to increase congruence between theory and practice and better support patients, it is imperative that we gain an improved understanding of healthcare professionals' behavior and the determinants that underlie their behavior.

Cardiovascular risk factors, namely abdominal obesity, high blood pressure, low HDL cholesterol (HDL-C), elevated triglycerides and elevated blood glucose levels, increase one's risk for cardiovascular disease, type 2 diabetes and all-cause mortality [8-11]. According to the classification based on the extended ATPIII criteria put forth by the National Cholesterol Education Program's Adult Treatment Panel III definition, people at cardiovascular risk are having one or more of the following risk factors: abdominal obesity (for men a waist circumference $>102 \mathrm{~cm}$ and for women $>88 \mathrm{~cm}$ ); high blood pressure (with a systolic blood pressure of $\geq 130 \mathrm{~mm}$ $\mathrm{Hg}$, or diastolic $\geq 90 \mathrm{mmHg}$, or being on antihypertensive drug treatment); people with low HDL cholesterol (high-density lipoprotein, for men $<1.03 \mathrm{mmol} / \mathrm{L}$, for women $<1.30 \mathrm{mmol} / \mathrm{L}$ ) or being on medication; elevated triglycerides $(\geq 1.70 \mathrm{mmol} / \mathrm{L}$, or being on medication that reduces triglycerides, and; elevated blood glucose $(\geq 6.1 \mathrm{mmol} / \mathrm{L}$, or being on medication that reduces blood glucose $[8,9]$.

The number of patients with cardiovascular risk factors is increasing and the prevalence is being exacerbated by decreasing physical activity levels $[9,10,12]$. Research has demonstrated that physical activity and physical fitness have a preventive effect on cardiovascular morbidity and mortality [13-17]. Physical activity and physical fitness are associated with important health benefits for every cardiovascular risk factor and also for the group of interrelated risk factors. Physical activity and physical fitness can have a beneficial effect on lipids, blood pressure, glucose metabolism, and on body composition $[9,11,18-27]$. In a recent study on physical activity, we found that particularly (high) intensity physical activity impacts cardiovascular risk factors and concluded that interventions should focus on high intensity physical activity leading to physical fitness [28].

In order to enable the development of effective cardiovascular disease prevention interventions, we must understand how healthcare professionals can best be engaged to promote an active lifestyle in cardiovascular patients. Consequently, in this study, we investigated the social-cognitive determinants of healthcare professionals' intention to encourage physical activity among cardiovascular patients as posited by the Theory of Planned Behavior and other relevant social psychological theories [29-38]. The Theory of Planned Behavior is considered appropriate for explaining both healthcare professionals' intentions and behavior $[1,5,30]$.

According to the Theory of Planned Behavior, healthcare professionals' behavior of encouraging physical activity among cardiovascular patients is predicted by their intention to encourage physical activity among these patients and behavior is also determined by habits and barriers. Behavioral intention can be explained by three social-cognitive determinants, namely attitude, subjective norm, and perceived behavioral control [38]. Attitude refers to the general evaluation of the behavior, and is determined by behavioral beliefs (perceptions regarding the advantages and disadvantages of the behavior) and perceptions regarding the consequences of the behavior. The subjective norm refers to the perceived social approval for the behavior, and is determined by expectations regarding whether important reference individuals or groups will approve of the behavior. In addition to the subjective norm, the descriptive norm from Bandura's Social Cognitive Theory is an extension of the Theory of Planned Behavior [39]. The descriptive norm can be considered as the behavior of others in the social environment. The moral norm, also an extension of the Theory of Planned Behavior, is essential as the individuals' responsibility and the individuals' moral obligation towards the behavior to act in a specific way [30]. Perceived behavioral control is one's confidence in one's ability to perform a specific behavior and is determined by control beliefs that are based on perceptions of opportunities as well as perceived barriers and required resources [38].

People intend to engage in behaviors when the behavior is evaluated as positive, when one thinks that significant others find the behavior to be important, and when the behavior is considered to be under personal control. Behavior can be predicted by intention, barriers and habit [33]. Habit, as an extension of the Theory of Planned Behavior, can influence the intention-behavior relationship. Habit is determined by past behavior and concerns the individuals' personal experience with a specific behavior in a stable context, such as a healthcare setting [40]. Barriers can obstruct the behavior, even though the intention to engage in the behavior is positive. According to the Theory of Planned Behavior, the influence of general dispositions and socio-demographic factors are mediated by attitude, subjective norms and perceived behavioral control. 
In order to make cardiovascular prevention and the implementation of interventions directed at optimizing the health status of cardiovascular patients effective, it is imperative that we gain a better understanding of healthcare professionals' behavior and intentions, and the social-cognitive determinants of behavior and intentions. The aims of this study were first to explore the relative importance of social-cognitive variables in relation to healthcare professionals' intention and behavior. Secondly we investigated the congruence between healthcare professionals' intention to encourage physical activity in cardiovascular risk patients and the selfreported behavior of encouraging patients.

\section{Methods}

In the Professionals' Intention and Behavior (PIB) study, healthcare professionals completed online surveys measuring their intention to encourage physical activity among cardiovascular risk patients, their self-reported behavior of encouraging cardiovascular risk patients, the social-cognitive determinants of their intentions and behavior, and demographic variables. Participants were recruited from the Department of Physiotherapy and Department of Nursing at the University of Applied Sciences in the Netherlands. Participants were (former) students of the University of Applied Sciences in the Netherlands. Healthcare professionals with at least a Bachelor's degree in nursing (approximately $40 \%$ of the study group) or physiotherapy (60\% of the study group) and who conduct consultations with cardiovascular risk patients were included in the analyses. In total 739 were invited to complete the online survey, with three reminders send. 572 healthcare professionals completed the survey at time 1 (T1, April 2009) and of those, 278 professionals completed the survey at time 2 (T2, October 2009). Statistical analysis in separated groups revealed no differences between healthcare professionals' with a background in physiotherapy or nursing. The ethics committee of the Maastricht University, The Netherlands, granted approval to the study (Trial ID: ECP-92).

\section{Assessment of social-cognitive determinants}

The survey content was derived from a literature review and in-depth interviews with professionals on how they encourage cardiovascular patients to engage in and maintain physical activity. There were eight elicitation interviews held, four with healthcare professionals with a background in physiotherapy and four in nursing. Four of those professionals were observed in their professional activities for a regular working day. For measuring social-cognitive determinants, no valid questionnaires are available, but only valid procedures. The construction of the questionnaire is, according to the Theory of Planned Behavior, specific to the definition of the behavior and the specification of the research population $[33,41]$. The questionnaire was piloted, as a result no revisions were made. We collected data at time 1 (T1) and time 2 (T2). At T1 the baseline measurement, we measured all social-cognitive determinants except self-reported behavior. At T1 all socialcognitive determinants underlying behavior were investigated. At T2 the follow-up measure, we measured selfreported behavior. By measuring social-cognitive determinants at T1 (social-cognitive determinants) followed by T2 (behavior) makes it possible to predict behavior from intention.

Behavior was assessed by averaging two items: 'Do you encourage cardiovascular patients to become physically active?'. And 'In the past month, how many of your cardiovascular patients did you encourage to become physically active?'. Answers ranged from 'none' (1) to 'all' (7) on a seven-point scale (Cronbach's $\alpha=.64$ ). Behavior was also dichotomized as encouragement versus no encouragement. For dichotomizing the social-cognitive determinant behavior, we calculated quintiles of the determinant score. The highest two quintiles were positioned as encouraging behavior and the lowest two quintiles were positioned as less encouragement. We left the $20 \%$ in between the two groups (encouraging vs. less encouraging) out, to make a clear distinction between groups.

Intention was indexed with three questions: 'Do you intend to encourage cardiovascular patients to become physically active tomorrow and the day after tomorrow?', 'Do you expect to encourage cardiovascular to become physically active tomorrow and the day after tomorrow?', and 'Of the first 10 cardiovascular patients you see, how many do you intend to encourage to become physically active?' (Cronbach's $\alpha=.82$ ). Answers ranged on a seven-point scale ( $1=$ 'definitely not' to 7 = 'most definitely'), except for the question 'Of the first 10 cardiovascular patients .... We recalculated this question on a 10-point scale multiplying it by 0.7 . Intention was also dichotomized as high versus low intention. For dichotomizing the social-cognitive determinant intention, we calculated quintiles of the determinant score. The highest two quintiles were positioned as having a high intention and the lowest two quintiles were positioned as having a low intention. We left the $20 \%$ in between the two groups (high vs. low intention) out, to make a clear distinction between groups.

Attitude was assessed by ten items on a seven-point scale. Answers ranged on a seven-point scale $(1=\mathrm{bad} /$ very useless to $7=$ good/very useful). First we asked 'In my view, encouraging cardiovascular patients to become physically active is very good - very bad' and 'Encouraging cardiovascular patients is very useful - very useless'. Then we asked, 'Is it useful to: assess patients' 
motivation, assess the pros and cons of physical activity, teach patients how to resist social pressure, teach patients specific skills pertaining to physical activity, teach patients how to handle barriers in regard physical activity, formulate physical activity goals together with patients, teach patients how to handle relapses, and help patients understand the relationship between the specific health problem and physical inactivity?'. These eight items ('Is it useful to ...') were averaged and that score was averaged with the first two item scores to represent attitude (Cronbach's $\alpha=.63$ ).

Perceived behavioral control was assessed by 11 questions on a seven-point scale. First we asked, 'Do you think that you have the skills and knowledge to encourage cardiovascular patients to become physically active?'. We then asked: 'Do you think you can rely on your skills and knowledge to encourage cardiovascular patients to become physically active?'. Answers ranged from 'no, certainly not' (1) to 'yes, certainly' (7) on a seven-point scale. Thirdly we asked 'Encouraging every cardiovascular patients to become physically active is very difficult (1) - very easy (7)'. Perceived behavioral control was further assessed by an eight item scale that paralleled the eight item scale used for attitudes. 'It is very difficult (1) - very easy (7) to: assess patients' motivation, assess the pros and cons of physical activity, teach patients how to resist social pressure, teach patients specific skills pertaining to physical activity, teach patients how to handle barriers in regard physical activity, formulate physical activity goals together with patients, teach patients how to handle relapses, and help patients understand the relationship between the specific health problem and physical inactivity?'. Once again this scale score was calculated and combined with the previous three items as a measure of perceived behavioral control (Cronbach's $\alpha=.78$ ).

Subjective norm was measured by four items: 'Most colleagues who are important to me think I should encourage cardiovascular patients to become physically active', 'Most colleagues value that I encourage cardiovascular patients to become physically active', 'Patients value that I encourage them to become physically active', and 'The organization I work for values that I encourage cardiovascular patients to become physically active'. Answers ranged from 'no, certainly not' (1) to 'yes, certainly' (7) on a seven-point scale (Cronbach's $\alpha$ $=.73)$.

Descriptive norm was indexed by four items: 'Do you encourage more cardiovascular patients to engage in physical activity than your colleagues do?', 'Do you encourage more cardiovascular patients to engage in physical activity than professionals that have the same academic background as you do?', 'Most colleagues encourage patients to engage in physical activity themselves', and 'Do you consult colleagues when you experience problems encouraging cardiovascular patients to become physically active?'. Answers ranged from 'no, certainly not' (1) to 'yes, certainly' (7) on a seven-point scale (Cronbach's $\alpha=.61$ ).

Moral norm was assessed by three questions: 'Encouraging patients to engage in physical activity is my professional duty', 'Encouraging patients to engage in physical activity is a moral obligation', and 'Encouraging patients to engage in physical activity is an obvious part of my job'. Responses were provided on a sevenpoint scale ranging from 'definitely not' (1) to 'most definitely' (7) (Cronbach's $\alpha=.76$ ).

Habit was measured by two questions [40]: 'Encouraging patients to be physically active is something I do without thinking', and 'Encouraging patients to be physically active is something I do automatically'. Answers ranged on a seven-point scale $(1=$ 'definitely not' to $7=$ 'most definitely') (Cronbach's $\alpha=.75)$.

Barriers were indexed by two questions that focused on encouraging patients 'even when one is busy' and 'even when one's organization makes it difficult to encourage patients'. Answers ranged from 'no, certainly not' (7) to 'yes, certainly' (1) on a seven-point scale (Cronbach's $\alpha=.69$ ). In this way, we measure perceived barriers, which may be part of perceived behavioral control. Because barriers are relevant in an organizational context, we measured them separately.

A determinant score was calculated for every socialcognitive determinant. Per social-cognitive determinant we summed up the scores on the questions and divided this by the number of items.

\section{Statistical analysis}

Descriptive statistics were first calculated and Chisquare analysis was used to explore the population under study. Subsequently, a correlation matrix of all social-cognitive determinants was generated. To explore the congruence between professionals having a high or low intention and encouraging or no encouraging behavior, Chi-square analyses were conducted on dichotomized variables. Hierarchical regression analyses were then applied to model healthcare professionals' intention and behavior. To do this, we analyzed the association between: 1) intention at $\mathrm{T} 1$ and the social-cognitive determinants; entering attitude, perceived behavior control and subjective norm in the first block, and entering descriptive norms and moral norms in the second block of hierarchical regression. 2) behavior at T2, and intention at T1 together with the social-cognitive determinants; entering intention in the first block and habit and barriers in the second block of hierarchical regression. Significance was set at $\mathrm{p}<.05$. Statistical analyses were undertaken with SPSS version 17.0 (SPSS inc. 2009). 
Table 1 Characteristics of the study population

\begin{tabular}{ll}
\hline $\mathbf{N}=\mathbf{2 7 8}$ & \\
\hline Male & $26.3 \%(73)$ \\
Female & $73.7 \%(205)$ \\
Age, years & $36.2 \pm 10.1$ \\
Professional experience, years & $8.58 \pm 7.70$ \\
$\begin{array}{l}\text { Completed Bachelor's degree in nursing or } \\
\text { physiotherapy }\end{array}$ & $37.8 \%(105)$ \\
$\begin{array}{l}\text { Completed or currently acquiring a degree above } \\
\text { Bachelor's level }\end{array}$ & $31.3 \%(87)$ \\
$\begin{array}{l}\text { Completed or currently acquiring a Master's degree in } \\
\text { nursing or physiotherapy }\end{array}$ & $30.9 \%(86)$ \\
Consultation time devoted to health education & $60.4 \%$ \\
Average number of consultations with one patient & $10.1 \pm 12.2$ \\
Minimum number of consultations with one patient & $3.69 \pm 4.23$ \\
\hline
\end{tabular}

Values are percentages (and numbers) or mean \pm SD

\section{Results}

Table 1 presents descriptive statistics for the study population. We found that $73.7 \%$ of the healthcare professionals were female. The mean age was 36.2 years $( \pm 10.1)$. In the sample, about $40 \%$ completed a Bachelor's degree in nursing or physiotherapy and about $60 \%$ were studying at a level above Bachelor's degree or had completed an additional degree after their Bachelor's degree. Statistical analysis in separated groups revealed no differences between healthcare professionals' with a background in physiotherapy or nursing $(\mathrm{p}<0.05)$. Healthcare professionals had $8.58( \pm 7.70)$ years experience working as a professional. They reported to have at least $3.69( \pm 4.23)$ consultations with one patient. The average number of consultations was $10.1( \pm 12.2)$ with one patient. Also, participants indicated that $60.4 \%( \pm 25.2)$ of their consultation time is spent on health education.

The correlation matrix (table 2) shows positive correlations between healthcare professionals' intention to encourage physical activity among cardiovascular patients and behavior (a moderate to strong association, $r=.44)$. According to the Theory of Planned Behavior, healthcare professionals' intention is determined by their attitude, the subjective norm and their perceived behavioral control in addition to moral and descriptive norms. Positive correlations were found between intention and attitude (a strong association $r=.59$ ), subjective norm (a moderate-to-strong association, $r=.45$ ), perceived behavioral control (a moderate-to-strong association, $r=.41$ ), descriptive norm (a weak-to-moderate association, $r=.25$ ), and moral norm (a weak association, $r=.14$ ). Healthcare professionals' behavior was found to be positively related to perceived behavioral control (a weak-to-moderate association, $r=.28$ ) and the habit of encouraging patients to engage in physical activity (a moderate association $r=.30$ ). As expected, a moderate-to-strong negative association between barriers and self-reported behavior was found $(r=-.40)$.

\section{Congruence between healthcare professionals' intention and behavior}

Analyses were undertaken to explore the congruence between the healthcare professionals' intention to encourage physical activity among cardiovascular patients and the self-reported behavior of encouraging patients (table 3 ). For behavior, we found that $56.8 \%$ of the healthcare professionals encourage physical activity among cardiovascular patients. For intention, we found that $51.3 \%$ of the healthcare professionals reported positive intentions to encourage physical activity among cardiovascular patients. In terms of congruence between intention and behavior, $39.7 \%$ of the healthcare professionals reported both positive intentions and the corresponding behavior of encouraging physical activity among cardiovascular patients. $31.7 \%$ of the professionals scored low on intention and had the corresponding behavior of not encouraging patients to engage in

Table 2 Correlations between behavior, intention and social-cognitive determinants

\begin{tabular}{|c|c|c|c|c|c|c|c|c|c|}
\hline$N=278$ & BehT2 & IntT1 & Att & PBC & SN & DN & MN & $\mathrm{Hab}$ & Barr \\
\hline Behavior Time 2 & BehT2 & & & & & & & & \\
\hline Intention Time 1 & $.44^{* * *}$ & IntT1 & & & & & & & \\
\hline Attitude & $27^{* * *}$ & $.59^{* * *}$ & Att & & & & & & \\
\hline Perceived behavioral control & $28^{* * *}$ & $.41^{* * *}$ & $.43^{* * *}$ & PBC & & & & & \\
\hline Subjective norms & $.25^{* * *}$ & $.45^{* * *}$ & $.43^{* * *}$ & $.43^{* * *}$ & SN & & & & \\
\hline Descriptive norms & $29 * * *$ & $.25^{* * *}$ & $.25^{* * *}$ & $.34^{* * *}$ & $.50^{* * *}$ & DN & & & \\
\hline Moral norms & ns & $.14^{*}$ & ns & ns & ns & ns & MN & & \\
\hline Habit & $.30^{* * *}$ & $.27^{* * *}$ & $.16^{* *}$ & $.40^{* * *}$ & $.19^{* *}$ & $.21^{* *}$ & ns & $\mathrm{Hab}$ & \\
\hline Barriers & $-.40^{* * *}$ & $-.38^{* * *}$ & $-.39 * * *$ & $-.42^{* * *}$ & $-.40^{* * *}$ & $-.33^{* * *}$ & ns & $-.37^{* * *}$ & Barr \\
\hline Mean & 5.77 & 6.20 & 6.18 & 5.04 & 5.63 & 4.86 & 5.57 & 5.29 & 2.64 \\
\hline SD & 0.91 & 0.94 & 0.60 & 0.60 & 0.77 & 0.72 & 1.13 & 1.26 & 1.00 \\
\hline Range & $1-7$ & $1-7$ & $1-7$ & $1-7$ & $1-7$ & $1-7$ & $1-7$ & $1-7$ & $1-7$ \\
\hline
\end{tabular}

Values represent correlation coefficients.

*** $p<0.001,{ }^{* *} p<0.01,{ }^{*} p<0.05$. 
Table 3 High and low intention at T1 versus the presence or absence of behavior that encourages physical activity in cardiovascular patients at T2

\begin{tabular}{llll}
\hline $\mathbf{N = 1 9 9}$ & Behavior T2 & & \\
\hline & Encouragement & No encouragement & Total \\
\hline Intention high T1 & $69.9(79)$ & $26.7(23)$ & $51.3(102)$ \\
& 39.7 & 11.5 & \\
Intention low T1 & $30.1(34)$ & $73.3(63)$ & $48.7(97)$ \\
& 17.1 & 31.7 & \\
Total & $56.8(113)$ & $43.2(86)$ &
\end{tabular}

Chi-square-analysis, $\mathrm{p}<0.05$;

Values represent percentages and (numbers); italics represent the percentage of the total group.

physical activity. In addition, $17.1 \%$ of the healthcare professionals demonstrated behavior that encourages physical activity among cardiovascular patients despite low intention. Also, $11.5 \%$ of the professionals had high scores on intention but failed to perform the selfreported behavior of encouraging physical activity among cardiovascular patients.

Healthcare professionals with high versus low intention differed on all social-cognitive determinants $(\mathrm{p}<$ $.05)$. Also, healthcare professionals that engaged in the behavior of encouraging physical activity among cardiovascular patients differed significantly from those who did not on all social-cognitive determinants except on moral norm $(\mathrm{p}<.05)$ (see table 4$)$.

\section{Intention and behavior predicted by social-cognitive variables}

Regression analyses identified correlates of healthcare professionals' intention to encourage physical activity among cardiovascular patients and the behavior of encouraging these patients (table 5). Social-cognitive variables accounted for $41 \%(\mathrm{p}<.001)$ of the variance in intention. Intention was, in turn, predicted by attitude $(\beta=.443, \mathrm{p}<.001)$, subjective norms $(\beta=.201, \mathrm{p}<$ $.001)$, and perceived behavioral control $(\beta=.137, \mathrm{p}<$ $.05)$. With respect to the self-reported behavior of encouraging physical activity among cardiovascular patients, $29 \%$ of the variance $(\mathrm{p}<.001)$ was explained by intention $(\beta=.311, \mathrm{p}<.001)$, next to habit $(\beta=.163$, $\mathrm{p}<.01)$ and barriers $(\beta=-239, \mathrm{p}<.001)$. With respect to the self-reported behavior, intention showed the strongest predictor, and additional predictors were the habit of encouraging patients to engage in physical activity and barriers that obstruct the encouragement of patients to engage in physical activity.

\section{Discussion}

The study reported here explored healthcare professionals' intention to encourage physical activity among cardiovascular patients and the subsequent behavior of encouraging patients. We investigated the relative importance of social-cognitive variables derived from the Theory of Planned Behavior and other relevant social psychological theories in relation to healthcare professionals' intention and behavior, and the congruence between healthcare professionals' intention and behavior.

In this study, we demonstrated that social-cognitive variables are useful predictors of both healthcare professionals' intention to encourage physical activity in cardiovascular patients and their self-reported behavior of encouraging patients. Social-cognitive variables accounted for $29 \%$ of the variance in behavior, and $41 \%$ of the variance in intention. We found that behavior was predicted by high levels of intention, established habits of encouraging patients and low levels of barriers. Our finding that behavior is largely predicted by intention corresponds with previous studies including studies that focus specifically on the behavior of healthcare professionals $[1,30,35,42,43]$.

Our results indicate that, among healthcare professionals, the intention to encourage physical activity among cardiovascular patients is strongly associated with attitude, subjective norms, and perceived behavioral control, and, to a lesser extent, descriptive and moral norms. That attitude, subjective norms and perceived behavioral control are significant predictors of intention is congruent with other research, including research focusing particularly on healthcare professionals' intention [1,5,29,30,34,44-46].

In a systematic review on the predictors of healthcare professionals' behavior, social-cognitive determinants predicted $35 \%$ of the variance in behavior and $59 \%$ of the variance in intention [30]. As in our study, a metaanalytic review showed that social-cognitive variables accounted for $27 \%$ of the variance in behavior and $39 \%$ of the variance in intention [34]. Previous studies have shown regression values of $36 \%$ for behavior and $42 \%$ to $66 \%$ for intention $[29,44,46]$. According to a meta-analysis and the above mentioned studies, the amount of variance in behavior explained in our study was smaller than the amount of variance in intention [42].

The social-cognitive determinants of healthcare professionals are consequently expected to be key objectives for cardiovascular morbidity-reducing interventions directed at increasing healthcare professionals' intention to encourage physical activity in cardiovascular patients and the behavior of encouraging patients. Our findings suggest that, in order to optimize healthcare professionals' behavior, strengthen both behavioral intention and habit are worthwhile, and reduce barriers.

In addition, our findings revealed that professionals with more positive attitudes, more positive subjective norms, and higher perceived behavioral control were 
Table 4 Overview scale: means for all items according to high versus low intention and presence versus absence of behavior encouraging physical activity in cardiovascular patients

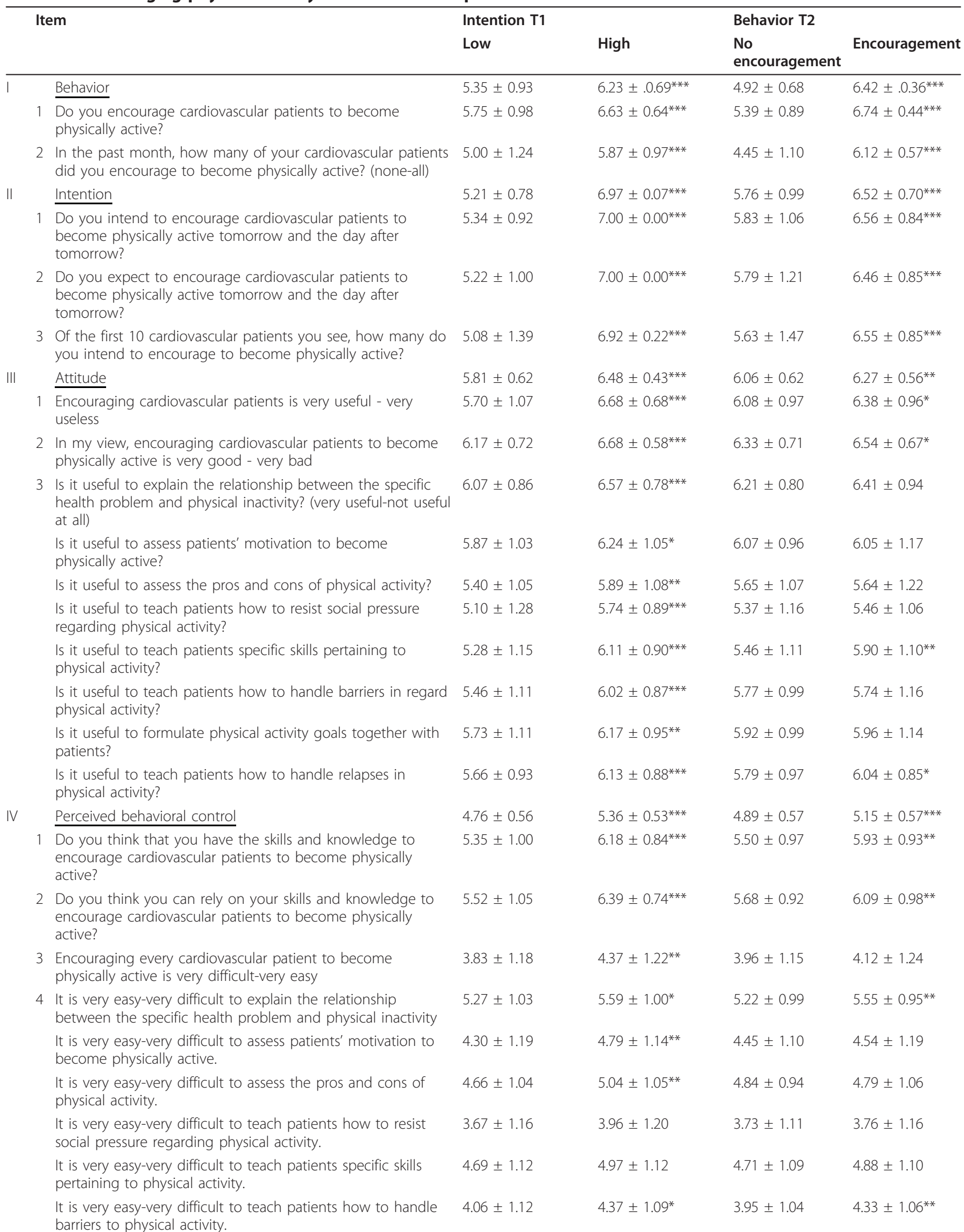


Table 4 Overview scale: means for all items according to high versus low intention and presence versus absence of behavior encouraging physical activity in cardiovascular patients (Continued)

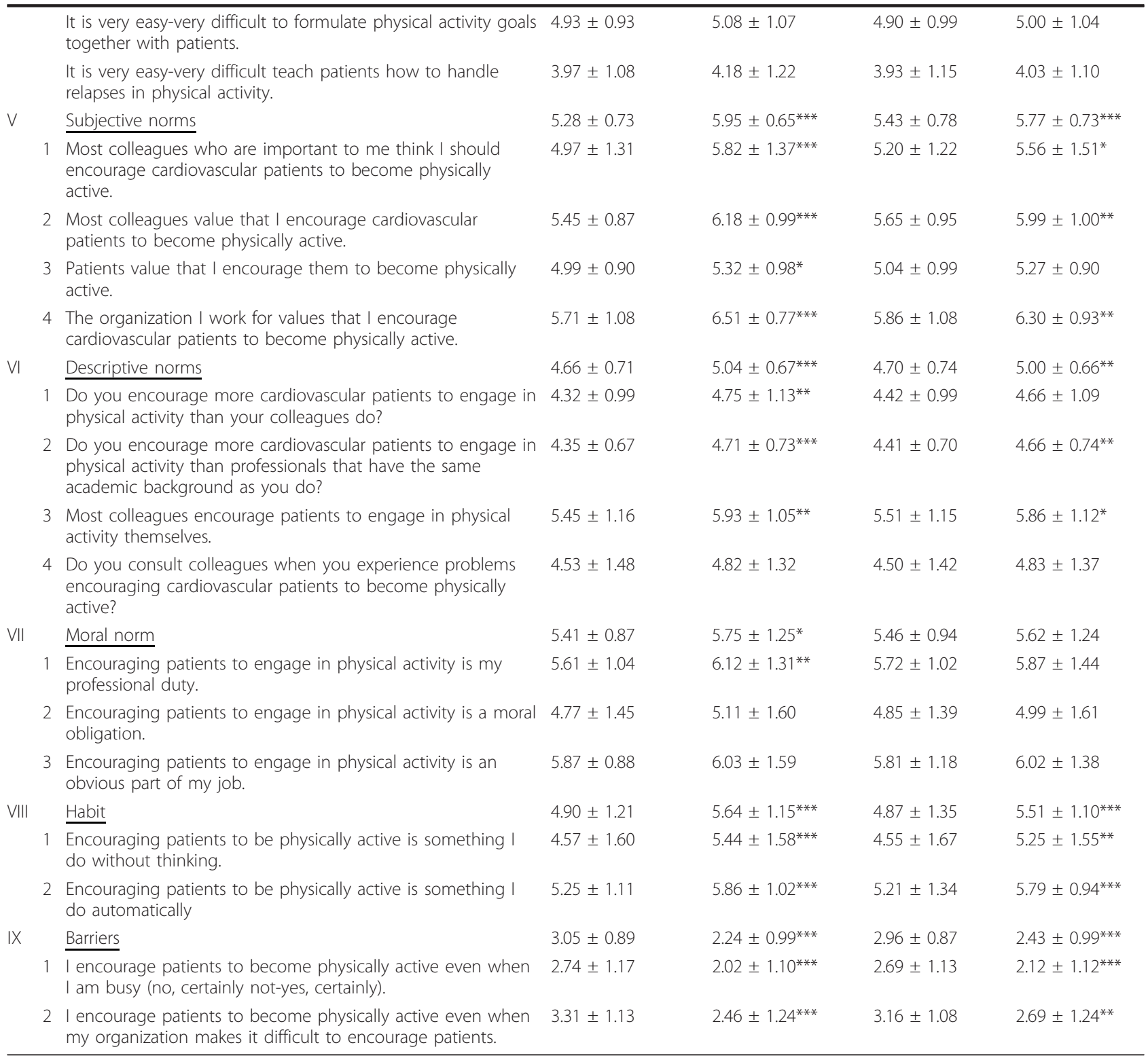

*** $p<.001,{ }^{* *} p<.01,{ }^{*} p<.05$.

more likely to have positive intentions to encourage physical activity in cardiovascular patients. Professionals perceived more advantages than disadvantages to encouraging cardiovascular patients to become physically active. Interventions should therefore endeavor to highlight and clarify the advantages of encouraging patients while providing explanations for the disadvantages. Healthcare professionals should get convinced that being physically active is important for patients with cardiovascular risk factors.

Also, subjective norms was in our study, found to be associated with intention, thus suggesting that professionals who felt that encouraging patients is expected and also done by other healthcare professionals had more positive intentions. Interventions should therefore be directed at seeking positive social support from other healthcare professionals, and learn to communicate the importance of encouraging patients to engage in physical activity with other healthcare professionals.

In our study, perceived behavioral control was found to be associated with the intention to encourage physical activity in cardiovascular patients, thus suggesting that professionals felt competent to perform the behavior 
Table 5 Predictors of intention at T1 and behavior that encourages physical activity in cardiovascular patients at T2

\begin{tabular}{lllll}
\hline $\boldsymbol{N}=\mathbf{2 7 8}$ & Intention & \multicolumn{3}{l}{ Behavior } \\
& $\mathrm{T}$ 1 & \multicolumn{1}{l}{$\mathrm{T}$ 2 } \\
& $\boldsymbol{r}$ & $\boldsymbol{\beta}$ & $\boldsymbol{r}$ & $\boldsymbol{\beta}$ \\
\hline Intention & & & $.44^{* * *}$ & $.311^{* * *}$ \\
Attitude & $.59^{* * *}$ & $.443^{* * *}$ & $.27^{* * *}$ & \\
$\begin{array}{l}\text { Perceived behavioral } \\
\text { control }\end{array}$ & $.41^{* * *}$ & $.137^{*}$ & $.28^{* * *}$ & \\
Subjective norms & $.45^{* * *}$ & $.201^{* * *}$ & $.25^{* * *}$ & \\
Descriptive norm & $.25^{* * *}$ & & $.29^{* * *}$ & \\
Moral norm & $.14^{*}$ & & $\mathrm{~ns}$ & \\
Habit & $.27^{* * *}$ & & $.30^{* * *}$ & $.163^{* *}$ \\
Barriers & $-.38^{* * *}$ & & $-.40^{* * *}$ & $-239^{* * *}$ \\
\hline $\mathrm{R}^{2}$ & & $.41^{* * *}$ & & $.29^{* * *}$ \\
\hline
\end{tabular}

Regression, ${ }^{* * *} \mathrm{p}<.001,{ }^{* *} \mathrm{p}<.01,{ }^{*} \mathrm{p}<.05$;

$r$ correlations;

$\beta$ beta's

and that encouraging patients was perceived as relatively easy to do. Interventions should support the feeling of competence and teach skills necessary to handle difficult situations encouraging patients to become or stay physically active.

The habit of encouraging patients can also contribute to behavior of encouraging patients and should therefore be consolidated via environmental interventions that strengthen such habits $[40,47]$. Our results suggest that investing in the development of the skills necessary to overcome barriers is worthwhile.

In addition to exploring the role of social-cognitive variables in the prediction of intention and behavior, we explored the relationships between intention and behavior. Do professionals with positive intentions actually encourage cardiovascular patients to become physically active? How many professionals have low intentions and do not engage in the behavior of encouraging patients to engage in physical activity? In our study, only $40 \%$ of the healthcare professionals had positive intentions and engaged in the self-reported behavior of encouraging patients and about $32 \%$ had low intentions and did not encourage cardiovascular patients to engage in physical activity. About $10 \%$ of the professionals had positive intentions but did not display the behavior of encouraging patients and about $17 \%$ had low intentions but nonetheless engaged in the behavior of encouraging patients to become physically active. This lack of congruence between high versus low intention and the behavior of encouraging patients versus not encouraging patients is an important input for interventions.

Interventions should be directed at strengthening the intention to encourage physical activity and the corresponding encouraging behavior for healthcare professionals. The social-cognitive determinants of intentions and behaviors may be changed in a more positive direction by planned interventions, deciding which determinants need to be changed, which need to be reinforced, and which need to be introduced $[41,48]$. To translate our results into an intervention for healthcare professionals aiming at increasing a positive intention towards encouragement of patients with cardiovascular risk factors and increasing their encouragement behavior, we will use Intervention Mapping. Intervention mapping provide a framework to built a systematically planned theory- and evidencebased intervention, highly applicable to the desired population and to improve the quality of interventions $[41,48]$. Intervention Mapping places specific emphasis on the input from social-cognitive determinants in the beginning of the development phases of an intervention.

Although the survey was specifically designed for the target population (nurses and physical therapists) with specific behavior (encouraging physical activity) for a specific group of patients (at risk for cardiovascular disease), it seems plausible that the basics could be used for other research. One strength of the study reported here is its longitudinal design as this ruled out the possibility that behavior caused intention [42]. The study's sample size is an additional strength. A possible limitation is that all of the professionals included in this study were recruited from the same institute and this may limit generalization of the outcomes. The measure of behavior is self reported and probably not very explicitly operationalized, this is also a possible limitation.

\section{Conclusions}

In order to prevent and limit cardiovascular risk via the improvement of risk behavior in patients, it is imperative that we understand healthcare professionals' intention to encourage physical activity in cardiovascular patients and subsequent behavior of encouraging patients. A major implication of this study is that healthcare professionals' intention to promote physical activity in cardiovascular patients and self-reported behavior of encouraging patients can be predicted by social-cognitive determinants. This implies that efforts to change behavior and strengthen the intention-behavior relationship of healthcare professionals to encourage physical activity in cardiovascular patients can optimize the cardiovascular risk profile of patients.

\section{Author details}

${ }^{1}$ Department of Health and Lifestyle, University of Applied Sciences, Utrecht, the Netherlands. ${ }^{2}$ Department of Work and Social Psychology, Maastricht University, Maastricht, the Netherlands. ${ }^{3}$ Department of Rehabilitation Sciences, KU Leuven, Leuven, Belgium. 


\section{Authors' contributions}

BS was involved in the study design, collected and analyzed the data, and took the lead in writing the manuscript. BS and GK designed the survey, contributed to the interpretation of the data, and provided feedback on the manuscript. All authors approved the final manuscript.

The original Dutch questionnaire is available for future research projects.

\section{Competing interests}

The authors declare that they have no competing interests.

Received: 1 October 2010 Accepted: 19 April 2011

Published: 19 April 2011

\section{References}

1. Eccles MP, Hrisos S, Francis J, Kaner EF, Dickinson HO, Beyer F, Johnston M: Do self-reported intentions predict clinicians' behaviour: a systematic review. Implement Sci 2006, 21:1-28.

2. Foley KA, Vasey J, Alexander CM, Markson LE: Development and validation of the hyperlipidemia: attitudes and beliefs in treatment (HABIT) survey for physicians. J Gen Intern Med 2003, 18:984-90.

3. Grimshaw JM, Eccles MP, Walker AE, Thomas RE: Changing physicians' behavior: what works and thoughts on getting more things to work. J Contin Educ Health Prof 2002, 22:237-43.

4. Grimshaw JM, Thomas RE, MacLennan G, Fraser C, Ramsay CR, Vale L, Whitty P, Eccles MP, Matowe L, Shirran L, Wensing M, Dijkstra R, Donaldson C: Effectiveness and efficiency of guideline dissemination and implementation strategies. Health Technol Assess 2004, 8:1-72.

5. Hrisos S, Eccles MP, Francis JJ, Bosch M, Dijkstra R, Johnston M, Grol R, Kaner EF, Steen IN: Using psychological theory to understand the clinical management of type 2 diabetes in Primary Care: a comparison across two European countries. BMC Health Serv Res 2009, 9:140.

6. Yeazel MW, Lindstrom Bremer KM, Center BA: A validated tool for gaining insight into clinicians' preventive medicine behaviors and beliefs: the preventive medicine attitudes and activities questionnaire (PMAAQ). Prev Med 2006, 43:86-91.

7. Perkins $M B$, Jensen $P S$, Jaccard J, Gollwitzer $P$, Oettingen $G$, Pappadopulos E, Hoagwood KE: Applying theory-driven approaches to understanding and modifying clinicians' behavior: what do we know? Psychiatr Serv 2007, 58:342-8.

8. Third Report of the National Cholesterol Education Program (NCEP): Expert Panel on Detection, evaluation and treatment of high blood cholesterol in adults (Adult Treatment Panel III). Final report National Institutes of Health; 2002.

9. Grundy SM, Cleeman JL, Daniels SR, Donato KA, Eckel RH, Franklin BA, et al: Diagnosis and management of the metabolic syndrome: An American Heart Association/National Heart and Lung, and Blood Institute Scientific Statement. Circulation 2005, 112:2735-2752.

10. Chobanian AV, Bakris GL, Black HR, Crushman WC, Green LA, Izzo JL, the National High Blood Pressure Education Program Coordinating Committee, et al: Hypertension 2003, 42:206-1252.

11. Lakka H, Laaksonen DE, Lakka TA, Niskanen LK, Kumpusalo E, Tuomilehto J, et al: The metabolic syndrome and total and cardiovascular disease mortality in middle-aged men. JAMA 2002, 288:2709-2716.

12. Eckel RH, Grundy SM, Zimmet PZ: The metabolic syndrome. Lancet 2005, 365:1415-28.

13. Berlin JA, Colditz GA: A meta-analysis of physical activity in the prevention of coronary heart disease. Am J Epidemiol 1990, 132:612-628.

14. Manson JE, Greenland P, LaCroix AZ, Stefanick ML, Mouton CP, Oberman A, Perii MG, Sheps DS, Pettinger MB, Siscovick DS: Walking compared with vigorous exercise for the prevention of cardiovascular events in woman. NEJM 2002, 347:716-7.

15. Sofi F, Capalbo A, Cesari F, Abbate R, Gensini GF: Physical activity during leisure time and primary prevention of coronary heart disease: an updated meta-analysis of cohort studies. Eur J Cardiovasc Prev Rehabil 2008, 15:247-57.

16. Nocon M, Hiemann T, Müller-Riemenschneider F, Thalau F, Roll S, Willich SN: Association of physical activity with all-cause and cardiovascular mortality: a systematic review and meta-analysis. Eur $\int$ Cardiovasc Prev Rehabil 2008, 15:239-46.
17. Myers J, Prakash M, Froelicher V, Do D, Partington S, Atwood JE: Exercise Capacity and Mortality among Men Referred for Exercise Testing. N Eng J Med 2002, 346(11):793-801.

18. Cornelissen VA, Fagard RH: Effects of endurance training on blood pressure, blood pressure-regulating mechanisms, and cardiovascular risk factors. Hypertension 2005, 46:667-675.

19. Halbert JA, Silagny CA, Finucane P, Withers RT, Hamdorf PA: Exercise training and blood lipids in hyperlipidemic and normolipidemic adults: a meta-analysis of randomized, controlled trials. Eur J Clin Nut 1999, 53:514-22

20. Gill JM: Physical activity, cardiorespiratory fitness and insulin resistance: a short update. Curr Opin Lipidol 2007, 18:47-52.

21. Shaw K, Gennat H, O'Rourke P, Del Mar C: Exercise for overweight or obesity. Cochrane Database Syst Rev 2006, 4:CD003817.

22. Rennie KL, McCarthy N, Yazdgerdi S, Marmot M, Brunner E: Association of the metabolic syndrome with both vigorous and moderate physical activity. Int J Epidemiol 2003, 32:600-6.

23. Ekelund U, Brage S, Franks PW, Hennings S, Emms S, Wong MY, et al: Physical activity energy expenditure predicts changes in body composition in middle-aged healthy whites: effect modification by age. Am J Clin Nutr 2005, 81:964-9.

24. Petrella RJ, Lattanzio CN, Demeray A, Varello V, Blore R: Can adoption of regular exercise later in life prevent metabolic risk for cardiovascular disease? Diabetes Care 2005, 28:694-701.

25. Hu G, Lakka TA, Kippeläinen TO, Tuomilehto J: Epidemiological studies of exercise in diabetes prevention. Appl Physiol Nutr Metab 2007, 32:583-95.

26. Lakka TA, Laaksonen DE, Lakka HM, Männikö N, Niskanen LK, Rauramaa R, et al: Sedentary lifestyle, poor cardiorespiratory fitness, and the metabolic syndrome. Med Sci Sports Exerc 2003, 35:1279-86.

27. Lamonte MJ, Barlow CE, Jurca R, Kampert JB, Church TS, Blair SN: Cardiorespiratory fitness is inversely associated with the incidence of metabolic syndrome: a prospective study of men and women. Circulation 2005, 112:505-12.

28. Sassen B, Cornelissen V, Kiers H, Wittink H, Kok GJ, Vanhees L: Physial fitness matters more than physical activity in controlling cardiovascular disease risk factors. Eur J Cardiovasc Prev Rehabil 2009, 16:667-683.

29. Godin G, Kok G: The theory of planned behavior: a review of its applications to health-related behaviors. Am J Health Promot 1996, 11:87-98.

30. Godin G, Bélanger-Gravel A, Eccles M, Grimshaw J: Healthcare professionals' intentions and behaviours: A systematic review of studies based on social cognitive theories. Implement Sci 2008, 16:3-36.

31. Ajzen I: The theory of planned behavior. Organizational Behavior and human Decision Processes 1991, 50:179-211.

32. Ajzen I: Perceived behavioral control, self-efficacy, locus of control, and the theory of planned behavior. J of Appl Social psychology 2002, 32:665-683.

33. Fishbein M, Aizen I: Predicting and changing behavior: the reasoned action approach New York: Psychology Press; 2010.

34. Armitage CJ, Conner M: Social Cognitive determinants of blood donation. J of Appl Social psychology 2001, 31:1-28.

35. Sheeran P, Trafimow D, Armitage CJ: Predicting behaviour from perceived behavioural control: tests of the accuracy assumption of the theory of planned behaviour. Br J Soc Psychol 2003, 42:393-410.

36. Rhodes RE, Courneya KS: Investigating multiple components of attitude, subjective norm, and perceived control: an examination of the theory of planned behaviour in the exercise domain. Br I Soc Psychol 2003, 42:129-46.

37. Rodgers WM, Conner M, Murray TC: Distinguishing among perceived control, perceived difficulty, and self-efficacy as determinants of intentions and behaviours. Br J Soc Psychol 2008, 47:607-30.

38. Bandura A: Self-efficacy: The exercise of control New York: Freeman; 1997.

39. Bandura A: Social foundations of thought and action: A social cognitive theory New York: Prentice Hall; 1987.

40. Verplanken B, Wood W: Interventions to break and create consumer habits. J Public Policy Mark 2006, 25:90-103.

41. Kok G, Schaalma H, Ruiter RA, van Empelen P, Brug J: Intervention mapping: protocol for applying health psychology theory to prevention programmes. J Health Psychol 2004, 9:85-98. 
42. Webb $T L$, Sheeran P: Does changing behavioral intentions engender behavior change? A meta-analysis of the experimental evidence. Psychol Bull 2006, 132:249-68.

43. Rhodes RE, Courneya KS, Blanchard CM, Plotnikoff RC: Prediction of leisuretime walking: an integration of social cognitive, perceived environmental, and personality factors. Int J Behav Nutr Phys Act 2007, $31: 4,51$.

44. Godin G, Conner M: Intention-behavior relationship based on epidemiologic indices: an application to physical activity. Am J Health Promot 2008, 22:180-2.

45. Hagger MS, Chatzisarantis N, Biddle SJH: The influence of self-efficacy and past behavior on the physical activity intentions of young people. J Sports Sci 2001, 19:711-23.

46. Boudreau F, Godin G: Using the Theory of Planned Behaviour to predict exercise intention in obese adults. Can J Nurs Res 2007, 39:112-25.

47. Brug J, de Vet E, de Nooijer J, Verplanken B: Predicting fruit consumption: cognitions, intention, and habits. J Nutr Educ Behav 2006, 38:73-81.

48. Bartholomew LK, Parcel GS, Kok G, Gottlieb NH: Planning Health Promotion Programs: An Intervention Mapping Approach San Francisco, CA: Jossey-Bass; 2006.

\section{Pre-publication history}

The pre-publication history for this paper can be accessed here:

http://www.biomedcentral.com/1471-2458/11/246/prepub

\section{Submit your next manuscript to BioMed Central and take full advantage of:}

- Convenient online submission

- Thorough peer review

- No space constraints or color figure charges

- Immediate publication on acceptance

- Inclusion in PubMed, CAS, Scopus and Google Scholar

- Research which is freely available for redistribution

Submit your manuscript at www.biomedcentral.com/submit 